\title{
Reproductive capacity and recurrence of disease after surgery for moderate and severe endometriosis - a retrospective single center analysis
}

Cordula Schippert $^{*+} \mathbb{D}$, Yvonne Witte ${ }^{\dagger}$, Janina Bartels, Guillermo-José Garcia-Rocha, Matthias Jentschke, Peter Hillemanns and Sudip Kundu

\begin{abstract}
Background: Endometriosis can be associated with considerable pain and sterility. After surgical excision of moderate or severe endometriosis lesions, the rate of recurrence reaches up to $67 \%$. The objective of this retrospective study was to establish the recurrence and pregnancy rates following surgical resection of stage III/IV endometriosis lesions. Indications for operation were endometriosis symptoms, sonographic findings and/or infertility.
\end{abstract}

Methods: A total of 456 patients who underwent stage III/IV endometriosis surgery between 2004 and 2014 were sent a questionnaire relating to their postoperative medical treatment, pregnancies, relief of symptoms and recurrence. Responses of 206 patients (45.2\%) and their clinical data were analysed for this study.

Results: A total of $66.5 \%(N=137)$ of patients had stage III disease, and 33.5\% ( $N=69)$ had stage IV disease. The average age was 37 years $(17-59)$. A total of $63.1 \%(N=130)$ of surgeries were performed by laparoscopy, $21.8 \%$ $(N=45)$ were performed by laparotomy and $15 \%(N=31)$ were performed by conversion. Complete resection of endometriosis lesions was achieved in $90.8 \%$ of patients ( $N=187)$. After surgery, $48.5 \%(N=100)$ of the women did not receive hormonal treatment; the main reason was the desire for children in $53 \%$.

Complete or partial relief in complaints was achieved in $93.2 \%(N=192)$. The rate of recurrence was $21.8 \%(N=45)$. The statistically significant factors that was associated with a higher risk to develop recurrence was an age $<35$ ( $p<$ 0.005).

After surgery, $65.8 \%(79 / 120)$ of patients who wished to have children became pregnant. There was a statistically significant association among a higher postoperative pregnancy rate and age $<35(p<0.003)$ in multivariate logistic regression analysis and laparoscopic surgical access in univariate logistic regression analysis $(p<0.01)$.

(Continued on next page)

\footnotetext{
* Correspondence: Schippert.Cordula@mh-hannover.de

Cordula Schippert and Yvonne Witte are share first authorship.

Department of Obstetrics and Gynaecology, Hanover Medical School,

Carl-Neuberg-Straße 1, 30625 Hannover, Germany
}

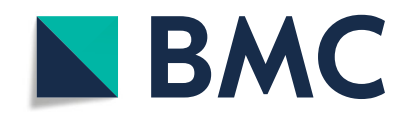

( The Author(s). 2020 Open Access This article is licensed under a Creative Commons Attribution 4.0 International License, which permits use, sharing, adaptation, distribution and reproduction in any medium or format, as long as you give appropriate credit to the original author(s) and the source, provide a link to the Creative Commons licence, and indicate if changes were made. The images or other third party material in this article are included in the article's Creative Commons licence, unless indicated otherwise in a credit line to the material. If material is not included in the article's Creative Commons licence and your intended use is not permitted by statutory regulation or exceeds the permitted use, you will need to obtain permission directly from the copyright holder. To view a copy of this licence, visit http://creativecommons.org/licenses/by/4.0/ The Creative Commons Public Domain Dedication waiver (http://creativecommons.org/publicdomain/zero/1.0/) applies to the data made available in this article, unless otherwise stated in a credit line to the data. 
(Continued from previous page)

Conclusion: We assessed the high percentage of complete or partial relief of symptoms of 93.2\%, the high postoperative pregnancy rate of $65.8 \%$ and the low rate of recurrence of $21.8 \%$ compared to international literature to be very encouraging for women suffering from moderate and severe endometriosis. Though laparoscopy is considered the 'gold standard'of endometriosis surgery, laparotomy still may be indicated in patients with extensive endometriosis especially to preserve reproductive function.

Keywords: Moderate endometriosis, Severe endometriosis, Recurrence, Pregnancy rate, Sterility, Reproduction, Surgical access

\section{Background}

Endometriosis can significantly decrease the quality of life of the affected women [1]. The effect of endometriosis on the quality of life concerns not only severe pain during menstruation, urination, defecation and intercourse but also psychological and social status as well as family planning [2]. From the onset of the first symptoms until the correct diagnosis is established, up to 7 years pass by on average [3]. Often, the pain has already become chronic at the time patients with endometriosis are diagnosed and receive treatment [1].

The prevalence of endometriosis is estimated at a minimum of $5-15 \%$ of all women of reproductive age [4]. Endometriosis is established in up to $80 \%$ of women suffering from lower abdominal pain and dysmenorrhoea [4-6].. The rASRM classification on the staging of endometriosis is practicable to use and makes it easier for patients to understand the extent of their disease [6, 7]. However, retroperitoneal structures and deeply infiltrating endometriosis lesions are not considered [7], and there is only a remote association between rASRM stage and pain intensity and frequency [8].

\section{Endometriosis and infertility}

Up to $50 \%$ of endometriosis patients suffer from infertility; in turn, up to $50 \%$ of the sterile women are diagnosed with endometriosis [6]. While the probability of achieving a pregnancy per menstruation cycle in healthy couples of reproductive age is between 15 and 20\%, this is, by contrast, in the range of 2 and $10 \%$ for women with endometriosis $[6,9]$. The exact causes for this decrease in fertility are not known. Peritubal and ovarian adhesions can affect the release and transport of the ovum. Increased inflammatory and angiogenic cytokines in the peritoneal fluid as well as autoantibodies to endometrial fragments may decrease fertility capacity [10]. Moreover, the ovarian reserve can be reduced in endometriosis patients. Studies show that patients with moderate or severe endometriosis without previous surgeries have lower levels of Anti-Mullerian Hormone (AMH) than healthy women $[11,12]$.

The surgical removal of endometriosis lesions, which can help reduce pain and improve fertility, is globally recognized as first-line therapy. In peritoneal endometriosis (Fig. 1), the primary therapy objective is the removal of all visible lesions [13].

In ovarian endometrioma, the cyst wall should be surgically removed completely [14]. However, it should be kept in mind that the resection of ovarian endometrial cysts can lead to a diminished ovarian reserve and therefore to a decrease in fertility $[12,15]$. ESHRE guidelines recommend laparoscopic resection of lesions of the disease to improve the spontaneous pregnancy rate in women with infertility with stage III or IV endometriosis [16]. In special cases of severe endometriosis with pronounced adhesions, tubal pathology or even recurrence, a laparotomy can also be indicated [17].

Ovarian endometriomas can be removed completely from the ovarian tissue without greater loss, as shown in the following Fig. 2a-d from our own hospital:

Extensive tubo-ovarian adhesions can be gently detached and the function of the fimbrial funnel can be restored so that spontaneous conception becomes possible (Fig. 3).

\section{Postoperative recurrence}

Unfortunately, the rate of recurrence after endometriosis surgery is considerable at times and varies between 6

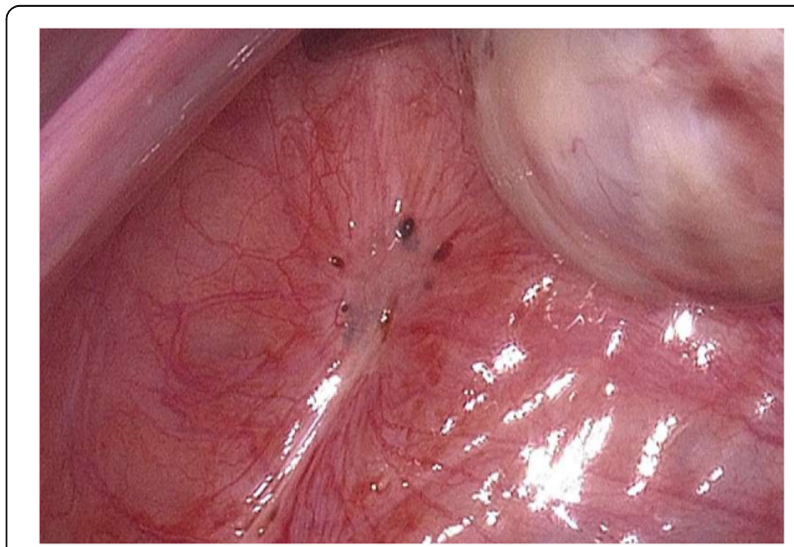

Fig. 1 Peritoneal endometriosis of the left pelvic wall (copyright remains with the authors). Typical livid lesions and an increased vascular pattern are visible 

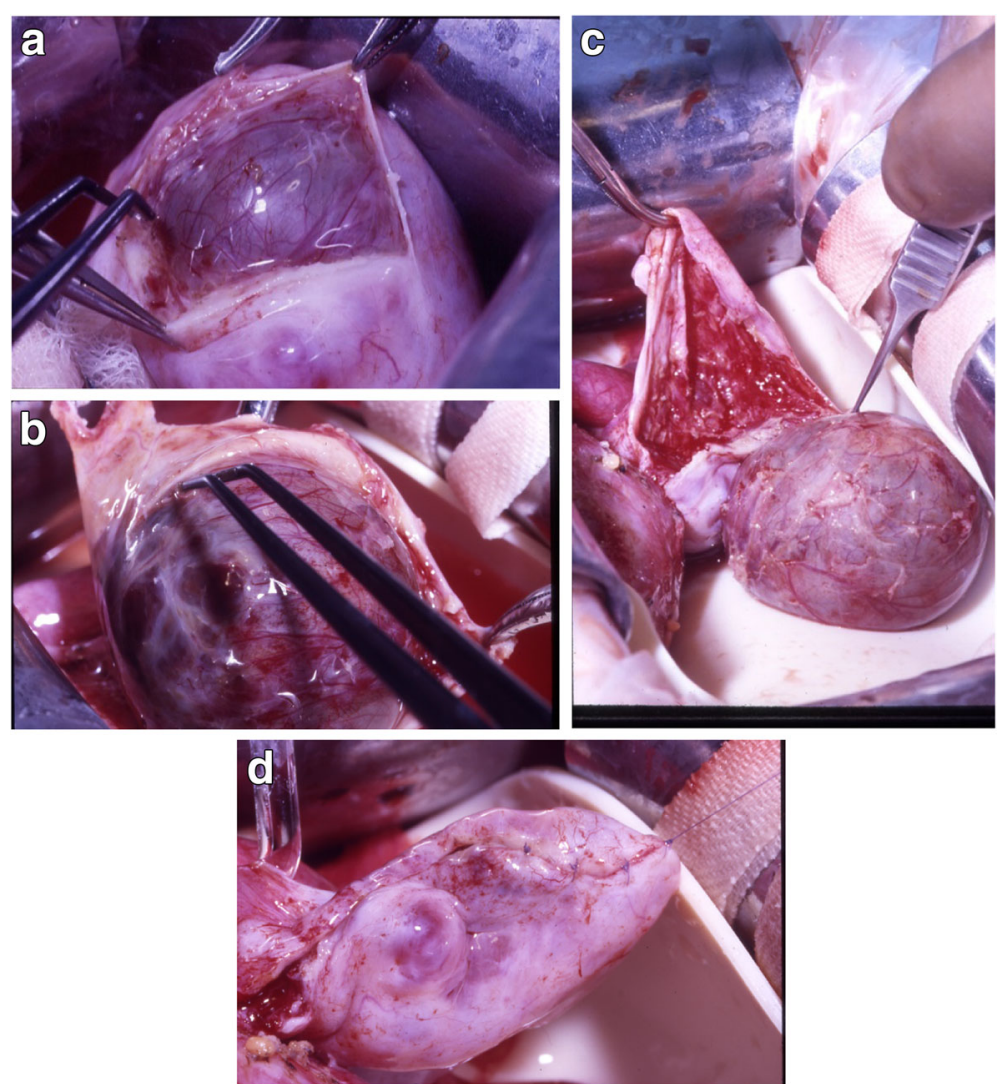

Fig. 2 a: Opening of the ovary with underlying endometrial cyst (copyright remains with the authors). b: Careful preparation and subsequent enucleation of the cyst without rupture (copyright remains with the authors). c: Careful preparation and subsequent enucleation of the cyst without rupture (copyright remains with the authors). $\mathbf{d}$ : Reconstruction of the ovary with 8-0 Vicryl suture (copyright remains with the authors)

and $67 \%$ after 5 years [18-22]. The rate of recurrence increases in relation to the extent of endometriosis at baseline [18]. Preoperative hormone therapy leads to a significant decrease in the spread of the disease measured with the rASRM score, but does not affect the postoperative symptoms and pregnancy rates whereas

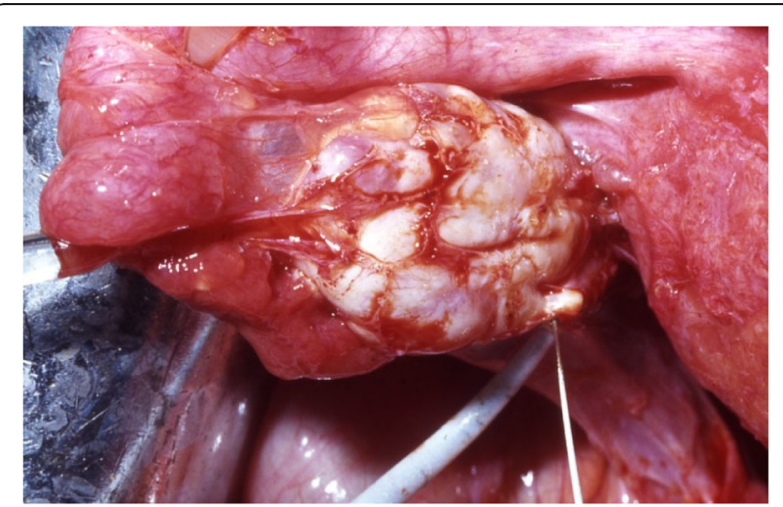

Fig. 3 Firm, endometriosis-related, tubo-ovarian adhesions (copyright remains with the authors) postoperative pharmacological therapy significantly decreases the rate of recurrence [23].

\section{Study objective}

The objective of this retrospective questionnaire-based study was to establish postoperative recurrence and pregnancy rates in patients after surgical resection of moderate and severe endometriosis lesions (rASRM stage III and IV). This was performed with a data analysis of patients who underwent surgery between 2004 and 2014 at the hospital. Indications for operation were typical endometriosis symptoms, sonographic findings (e.g., ovarian cysts) and/or infertility.

A subanalysis was used to study the extent of recurrence and pregnancy rates depending on disease stage and surgical access (laparotomy, conversion from laparoscopy to laparotomy), how often the surgery had to be extended by a bladder/intestinal surgical procedure and how often intra- and postoperative complications occurred.

\section{Methods}

This study was a retrospective review conducted at the Department of Gynecology and Obstetrics at Hannover 
Medical School (MHH) and was approved by the Ethics Committee of the MHH (no. 3527-2017). Written informed consent to participate in the study was obtained from all participants.

All premenopausal women who underwent surgery for moderate or severe endometriosis (rASRM stage III and IV) within a period of 11 years (2004 until 2014) were included in the study. Premenopausal status was defined as regular periods, the non-necessity of hormone replacement therapy, and the absence of menopause symptoms such as hot flashes or mood swings. Women with common benign comorbidities such as hypertension, autoimmune diseases or thyroid function disorders were included, whereas patients with malignant disease were excluded from the study. The surgeries were not performed during menstruation; otherwise, they were performed independently from the phase of the menstrual cycle.

By means of the hospital internal documentation programmes, a high number of 456 patients were identified who underwent surgery for histologically established grade III or IV endometriosis and fulfilled the inclusion criteria.

The following data were collected to obtain information about the inpatient hospitalization:

1. Demographic data such as age at the time of surgery and body mass index (BMI)

2. Previous endometriosis-related surgeries and preoperative pharmacological therapy

3. Surgical access (laparoscopy, laparotomy, conversion), the duration of surgery, the extent of surgical endometriosis lesions excision (complete, incomplete), and intra-/postoperative complications.

Furthermore, the patients were sent a questionnaire by post that was especially developed for the study to obtain data postoperatively. The questionnaire and has not been previously published elsewhere and is provided as Additional File 1.

Questions were asked about the following aspects:

1. Postoperative relief of symptoms as well as postoperative pharmacological therapy, if applicable

2. Development of a recurrence with the need for repeated surgery, including numbers and rASRM stage

3. If the patients had the desire to have children postoperatively: preoperative pregnancies and deliveries as well as postoperative pregnancies, the type of delivery and outcome regarding the child were included.
The statistical analysis was performed with the statistical software R (http://www.cran.r-project.org). After descriptive processing, a correlation analysis was performed, the significance of the correlation was tested and logistic regression was applied. Statistical significance was indicated if the $p$-value was less than 0.05 .

\section{Results}

Out of 456 patients who were primarily eligible for inclusion 206 sent back the questionnaires which corresponds to a response rate of $45.2 \%$. These 206 patients were included in the final analysis. A total of 137 (66.5\%) had stage III disease during surgery and 69 women $(33.5 \%)$ had stage IV disease.

\section{Demographic data}

The average BMI was 24.1 (SD $\pm 5.1 ; 14-44)$. The average age at surgery was 37 years $(\mathrm{SD} \pm 7 ; 17-59)$, and the majority of patients $(N=171 ; 83.0 \%)$ were under the age of 45.

A total of $38.8 \%$ of the women $(80 / 260)$ had already undergone previous surgery for endometriosis. The average number of endometriosis-related previous surgeries was 0.5 ( $\mathrm{SD} \pm 1.01 ; 0-9$ ). The stages of previous endometriosis disease could not be analysed separately because they were unknown in most cases.

Preoperative pharmacological therapy was performed in $30.6 \%(63 / 206)$ of patients for 4.4 months on average with a maximum of 10.6 months. The following products were used: $\mathrm{GnRH}$ analogues $(N=29)$, gestagen $(N=16)$, combined oral contraceptives $(N=13)$, and unknown substances $(N=3)$. Two patients received substances in combination (a GnRH analogue and a gestagen).

\section{Surgical data and procedures and intra- and postoperative complications}

The overall average duration of surgery was $122 \mathrm{~min}$ (SD $\pm 75.7 ; 20-424)$. In $63.1 \%(N=130)$ surgery was performed by laparoscopy, with an average duration of surgery of $81 \mathrm{~min}(\mathrm{SD} \pm 46.1 ; 20-424)$. Laparotomy was performed in $21.8 \%(N=45)$ of patients, with an average duration of surgery of $189 \mathrm{~min}(\mathrm{SD} \pm 69.1 ; 65-419)$. Here, some of the patients also underwent tubal surgical procedures under the surgical microscope so that the laparotomy was planned beforehand. In 31 patients (15\%), conversion from laparoscopy to laparotomy took place, and the surgery then lasted $202 \mathrm{~min}$ on average (SD $\pm 48.8 ; 125-327)$.

Complete endometriosis lesions excision was achieved in $90.8 \%$ of the women $(187 / 206)$. In 19 women, removal was incomplete $(9.2 \%)$. Reasons for this incomplete removal included the existing wish to have children, with 
a high risk of destroying ovaries and tubes or the risk of pronounced intestinal damage.

In a total of $8.3 \%$ of the patients (17/206), a surgical intestinal and bladder procedure was performed due to deep infiltrating endometriosis. In three patients (1.5\%), endometriosis lesions removal included bladder surgery with partial resection of the bladder and partial resection of the ureter. Fourteen patients (6.8\%) underwent intestinal surgery.

A total of $6.8 \%$ of the patients $(14 / 206)$ developed intra- and postoperative complications. In seven of these patients, the complications developed directly during surgical endometriosis lesions removal due to adhesions to the respective anatomical structures including damage to the rectum, bladder, ureter or distal part of the tube, and were treated immediately during surgery. A further seven patients developed general, minor intra- and postoperative complications (renal congestion, voiding dysfunction, wound healing disorders, Quincke's oedema, hypertensive crisis, iatrogenic injury of the peroneal nerve, cardiovascular instability, subfascial haematoma). Long-term morbidity did not occur.

\section{Postoperative interventions, decrease in symptoms and the rate of recurrence}

A total of $51.5 \%$ of the patients $(106 / 206)$ received postoperative pharmacological therapy for 26.9 months on average ( $\mathrm{SD} \pm 33.2)$. In $94.3 \%$, the therapy consisted only of one single active substance: a GnRH analogue, a gestagen preparation or combined oral hormones/contraceptives. Six of the 106 women received a combination of several of the abovementioned active substances after surgery. A total of 100 women (48.5\%) did not receive postoperative pharmacological therapy. The main reason for this was indicated as the active wish to have children directly after surgery.

Complete relief of symptoms was achieved in 76.6\% $(157 / 205)$ of women who answered this question. Partial relief of symptoms was achieved in 16.6\% (34/205). Fourteen patients $(6.8 \%)$ did not show any postoperative improvement. Symptoms were specified as dysmenorrhoea, intermittent bleeding, dyspareunia, hypermenorrhoea, pain during urination and defecation, ovulation pain, pain in the pelvic and sacral region, lower abdominal pain irrespective of the cycle and increased sensitivity to pain in the lower abdomen.

The stage of endometriosis had no effect on the relief of symptoms: 104 patients with stage III (75.9\%) and 53 patients with stage IV (76.8\%) developed symptom relief.

The rate of recurrence was $21.8 \%(45 / 206)$; therefore, surgery was necessary again over the course of follow-up.

\section{Effect of stage and surgical access on the rate of recurrence}

A total of $22.6 \%$ of the patients $(31 / 137)$ in stage III after surgery and $20.3 \%(14 / 69)$ of patients in stage IV developed recurrence $(p$-value $=0.7)$.

In patients with disease recurrence, laparoscopy was performed in $68.9 \%$ of cases (31/45), laparotomy in $22.2 \%(10 / 45)$ and conversion in $8.9 \%(4 / 45)$. The statistical analysis showed no association between the rate of recurrence and surgical access $(p$-value $=0.4)$. Additionally, with regard to the issue of a combined association among the rate of recurrence, stage and surgical access, no statistical significance was established.

\section{Postoperative rate of recurrence depending on the extent of excision}

After incomplete resection of endometriosis lesions, the rate of recurrence was $36.8 \%$ (7/19); after complete resection, the rate was only $20.3 \%(38 / 187)$. With 0.104 , the $p$-value of the regression coefficient was slightly over the threshold of significance.

After receiving postoperative pharmacological therapy, 29 of 106 women suffered a recurrence (27.4\%), whereas without subsequent treatment, recurrence occurred in $16 \%(16 / 100)$. This difference is statistically significant $(p$-value $=0.0496)$.

In the multivariate logistic regression analysis the variables maternal age, stage of endometriosis, surgical access, the extent of excision and postoperative pharmacological therapy are taken into consideration simultaneously. Statistically significant factors that were associated with a higher risk to develop recurrence were a lower maternal age $(p$-value $=0.00474)$ and the use of postoperative pharmacological therapy ( $p$-value $=$ 0.04993).

Postoperative fertility: wish to have children, pregnancy and birth rate, and neonatal outcome

Following surgical removal of the endometriosis lesions, 120 patients $(58.2 \%)$ had the desire to have children, and the majority were under 45 years of age $(N=117 ; 97.5 \%)$. Seventy-nine women became pregnant at least once as wished.

Approximately $70.4 \%(57 / 81)$ of the women after resection of stage III endometriosis lesions and $56.4 \%$ after resection of stage IV endometriosis lesions (22/39 women) became pregnant. Statistical significance was not observed here $(p$-value $=0.131)$. Overall, the postoperative pregnancy rate was $65.8 \%(79 / 120)$.

Twenty-nine women conceived twice and one patient each three, four and five times, respectively, after surgery. The average number of pregnancies was 1.4 $(\mathrm{SD} \pm 0.7 ; 1-5)$. 
The delivery rate (all birth modes) for the first pregnancy was $80.5 \%$ at the time of the survey. The children were born on average in the $39+3 / 7$ week of gestation, with an average weight for singleton pregnancies of $3254 \mathrm{~g}$. There were four twin pregnancies. At the time of the survey, two women were still pregnant in their first pregnancy. The delivery rate for the 2 nd postoperative pregnancy was $92.3 \%$.

A total of $76.0 \%$ of women who had been pregnant at least once before surgery became pregnant after surgery, while $61.4 \%$ of nulligravidae were able to conceive. Statistical significance was not seen here $(p$-value $=$ 0.4556).

\section{Influence of age, the stage of endometriosis, surgical access and the extent of excision on postoperative fertility}

A total of $76.7 \%$ of women up to and including the age of $34(56 / 73)$ and $48.9 \%$ of women from the age of 35 up wishing to have children $(23 / 47)$ became pregnant after surgery $(p$-value $=0.0017)$. This means that the chances of conception after surgery were significantly increased at a younger age up to 34 years.

After laparoscopic endometriosis surgery, 74.3\% (52/ 70) of women became pregnant after surgery, 61.3\% (19/

31) became pregnant after a laparotomy and $42.1 \%$ (8/

19) became pregnant after a conversion from laparoscopy to laparotomy. There was a statistically significant association between postoperative pregnancy rate and surgical access $(p$-value $=0.00893)$.

After incomplete resection, $41.5 \%$ (5/12) of women became pregnant, while $68.5 \%(74 / 180)$ of women were able to conceive after complete surgical excision.

With 0.063 , the p-value of the regression coefficient between the extent of removal and the postoperative pregnancy rate was slightly over the threshold of significance. Complete removal of the endometriosis lesions may increase the chance of future pregnancy.

In the multivariate logistic regression analysis the variables maternal age, stage of endometriosis, surgical access and the extent of excision are taken into consideration simultaneously. The dominant statistically significant factor that was associated with a higher postoperative pregnancy rate was the age $<35$ ( $p$-value $=$ 0.00267).

Table 1 summarizes the main results of the study.

\section{Discussion}

In this retrospective single center study presented here, we analysed the rate of recurrence of 206 premenopausal patients who underwent surgery for moderate to severe endometriosis in a period of 11 years and who completed the questionnaire sent to them. Unfortunately, the majority of the 456 patients that were primarily eligible for inclusion could no longer be contacted by post or telephone. Common benign comorbidities did not exclude the patients from the analysis, which, to our mind, represents a real cross section of the normal population.

We also analysed the pregnancy rate for 120 women who wanted to become pregnant after surgery. The majority of these women was under the age of $45(N=$ 117; 97.5\%).

Compared to other publications, this is a high number of patients. Recently, Sun et al. published a study with 59 infertile patients after laparoscopic cystectomy with six to 10 years of follow-up [24].

Our long follow-up period of four to 14 years after the index surgery enabled the registration and evaluation of the long-term efficacy of surgical endometriosis lesions resection with regard to the development of a recurrence and postoperative pregnancy. However, as a limitation of our study, the long follow-up period was problematic to the extent that a number of patients could no longer be reached per mail or telephone or through the attending physicians. After contacting 456 of the patients enrolled in the study, the return rate of the questionnaires was $45.2 \%$. This is, however, in the higher range when compared to other questionnaire-based studies [25-27]. We are aware that in these 11 years there were changes in term of diagnostic tools and detailed choice of postoperative treatment. Though, the principles of pharmacological therapy and as well the qualifications and skills of the operative personnel remained unchanged.

As Haas et al. [28] have shown in their retrospective epidemiological study, endometriosis affects young adolescents as well as perimenopausal women. Our study also included these women, so that overall, a cross section of all affected age groups was achieved. Obviously the fertility capacity decreases considerably over the age of 45 years; therefore, the low number of three women over the age of 45 years who were trying to become pregnant after surgery was to be expected.

Irrespective of the high number of patients analysed in this paper, we are fully aware that the retrospective approach and the questionnaire-based approach of the study limits the value of the results.

\section{Stage-related surgical procedures and postoperative rate of recurrence}

Surgical treatment for endometriosis is technically challenging and is sometimes similar in its complexity to the radical surgeries in gynaecological oncology. During the excision of extensive endometriosis lesions, close attention must be paid to the preferably complete removal of the endometriosis lesions and the preservation of the functional, reproductive structures in the minor pelvis. 
Table 1 Main results of the study

\begin{tabular}{|c|c|c|c|}
\hline & \multicolumn{3}{|c|}{ Proportions of patients in percent (number) } \\
\hline History of endometriosis surgery & \multicolumn{3}{|l|}{$38.8(80 / 206)$} \\
\hline Preoperative medical treatment & \multicolumn{3}{|l|}{$30.6(63 / 206)$} \\
\hline Preoperative pregnancies & \multicolumn{3}{|l|}{$39.8(82 / 206)$} \\
\hline Postoperative medical treatment & \multicolumn{3}{|l|}{$51.5 \%(106 / 206)$} \\
\hline Postoperative relief of symptoms (complete and partial) & \multicolumn{3}{|l|}{$93.2 \%(191 / 206)$} \\
\hline Postoperative recurrence rate & \multicolumn{3}{|l|}{$21.8 \%(45 / 206)$} \\
\hline $\begin{array}{l}\text { Postoperative pregnancy rate if women had the desire to have children } \\
(N=120)\end{array}$ & \multicolumn{3}{|l|}{$65.8 \%(79 / 120)$} \\
\hline $\begin{array}{l}\text { Postoperative birth rate in first and second pregnancy with regard to all } \\
\text { pregnancies }\end{array}$ & \multicolumn{3}{|l|}{$\begin{array}{l}80.5 \% \text { (first) } \\
92.3 \% \text { (second) }\end{array}$} \\
\hline \multirow[t]{2}{*}{ Postoperative total pregnancy rate depending from maternal age } & \multicolumn{3}{|c|}{$\begin{array}{l}\geq 34 \text { years: } 76.7 \%(56 / 73) \\
\leq 35 \text { years } 48.9 \%(23 / 47)\end{array}$} \\
\hline & $\begin{array}{l}\text { Stage III } \\
\text { (number) }\end{array}$ & Stage IV (number) & \\
\hline Intraoperative stage of endometriosis (rASRM) & $66.5(137 / 206)$ & $33.5(69 / 206)$ & \\
\hline Postoperative recurrence of disease & $22.6(31 / 137)$ & $20.3(14 / 69)$ & \\
\hline \multirow{2}{*}{$\begin{array}{l}\text { Postoperative pregnancy rate if women had the desire to have children } \\
(N=120)\end{array}$} & $70.4 \%(57 / 81)$ & $56.4 \%(22 / 39)$ & \\
\hline & $\begin{array}{l}\text { Laparoscopy } \\
\text { (number) }\end{array}$ & $\begin{array}{l}\text { Laparotomy } \\
\text { (number) }\end{array}$ & $\begin{array}{l}\text { Conversion } \\
\text { (number) }\end{array}$ \\
\hline Duration of surgery in minutes & 81 & 189 & 202 \\
\hline Proportion of patients in percent $(\mathrm{N})$ & $63.1(130)$ & $21.8(45)$ & $15(31)$ \\
\hline Postoperative recurrence rate with regard to surgical approach & $23.8(31 / 130)$ & $22.2(10 / 45)$ & $12.9(4 / 31)$ \\
\hline $\begin{array}{l}\text { Postoperative recurrence rate with regard to total number of recurrence } \\
(N=45)\end{array}$ & $68.9(31 / 45)$ & $22.2(10 / 45)$ & $8.9(4 / 45)$ \\
\hline \multirow{2}{*}{$\begin{array}{l}\text { Postoperative pregnancy rate if women had the desire to have children } \\
(N=120)\end{array}$} & $74.3 \%(52 / 70)$ & $61.3 \%(19 / 31)$ & $42.1 \%(8 / 19)$ \\
\hline & \multicolumn{3}{|c|}{ Proportions of patients in percent (number) } \\
\hline Proportion of complete resection of endometriosis in percent $(\mathrm{N})$ & $90.8(187 / 206)$ & $\begin{array}{l}\text { thereof postoperative } \\
\text { recurrence: } \\
20.3 \%(38 / 187)\end{array}$ & $\begin{array}{l}\text { thereof postoperative } \\
\text { pregnancy } \\
68.5 \%(74 / 180)\end{array}$ \\
\hline Proportion of incomplete resection of endometriosis in percent $(\mathrm{N})$ & $9.2(19 / 206)$ & $\begin{array}{l}\text { thereof postoperative } \\
\text { recurrence: } \\
36.8 \%(7 / 19)\end{array}$ & $\begin{array}{l}\text { thereof postoperative } \\
\text { pregnancy: } \\
41.5 \%(5 / 12)\end{array}$ \\
\hline Proportion of intestinal and/or urological surgeries in percent $(\mathrm{N})$ & \multicolumn{3}{|l|}{$8.3(17 / 206)$} \\
\hline Proportion of intra- and postoperative complications in percent $(\mathrm{N})$ & \multicolumn{3}{|l|}{$6.8(14 / 206)$} \\
\hline
\end{tabular}

Therefore, especially in women wanting to have children, patient age, previous pharmacological or surgical therapies and the extent of the disease must therefore be considered [29, 30]. Furthermore, the benefits of excessive surgery before IVF/ICSI are still uncertain and must be weighted carefully against the risks [15].

Complete surgical removal of endometriosis lesions was achieved in $90.8 \%(187 / 206)$ of our study population, which is - with respect to the high stages of disease - a high proportion. The most common reason for incomplete resection was the patient's existing wish to have children with the relevant high risk of serious destruction of the ovaries and tubes.
With $6.8 \%$, the peri- and postoperative rate of rather minor complications was low despite the partly very extensive disease and is in line with or even lower than the data published in literature [20, 30-32]. In half of these patients, the complications were associated with the immediate operative distance of the endometriosis lesions at the respective anatomical structures. The most common postoperative complication described was renal congestion [20], which developed in $1 \%$ of our study population.

The complete or partial relief of symptoms associated with endometriosis was achieved in $93.2 \%$ of our patient population, whereby complete remission of symptoms 
accounted for the largest percentage with $76.6 \%$. This result is high when compared with other published data [33-35]. We were not able to establish any differences in symptom relief regarding the rASRM stage, which also corresponds to the results of Vercellini et al. [36]. Comptour et al. [37] also demonstrated that laparoscopic endometriosis lesions resection irrespective of the rASRM stage has a positive, minimum three-year effect on both symptoms (lower abdominal pain, dyspareunia) and the quality of life.

A recurrence that led to repeated surgery developed in $21.8 \%$ of patients in our sturdy population. This value falls into the lower range of data published in the literature, where a recurrence rate of between 18.9 and $57 \%$ after 5 years is specified [18-20,22, 38-40]. It should be kept in mind that in some of our patients, 14 years had passed since surgery.

We were not able to establish a statistically significant association between recurrence rate and disease stage; there is discord in the literature in this regard. While Vercellini et al. [36] were not able to demonstrate an association between stage and risk of recurrence and attribute a rather low predictive power to the rASRM classification, Busacca et al. [41, 42] showed that both the rASRM stage as well as previous surgeries constituted influencing factors for recurrence. Tobiume et al. published data from 352 patients who underwent surgery of endometrioma and determined that only the rASRM score was correlated with a recurrence of $28.7 \%$ after 5 years [40].

Possible reasons for this discrepancy can be the difference in the technical performance of the surgery or the expertise of the surgeon, the definition of the measured endpoint (symptom relief or repeated surgery) as well as the length of the follow-up period and the patient population [19]. The studies of Busacca et al. [41, 42] focused on patients with stage III and IV endometriosis but defined the development of recurrence by means of postoperative sonographic findings and questionnaires without histological and/or laparoscopic confirmation. Vercellini et al. [36], on the other hand, examined patients of all rASRM stages and defined the development of recurrence by means of sonographic findings and a new surgical intervention. The findings of our study essentially correspond with the results of Vercellini et al. [36]. Our study only concentrated only on patients with moderate and severe endometriosis where the development of recurrence was defined by the need for new surgery with histological confirmation.

Even if the initial stage of endometriosis had no effect on recurrence in our study, recurrence developed more often in those with incomplete resection with $36.8 \%$ than in those with complete resection (20.3\%). However, this difference was not significant in our study, neither in univariate nor in multivariate analysis. These observations correspond with other publications [19, 39, 43].

Hormonal follow-up treatments are indicated after endometriosis surgery since they verifiably decrease the recurrence rates [43-46]. Thirty-five women in our population (33.0\%) received postoperative therapy with GnRH agonists, often as pre- and postoperative 'sandwich therapy', to ensure treatment success and optimize the likelihood of becoming pregnant in the long term.

A total of 100 women (48.5\%) in our population did not receive postoperative pharmacological therapy. In $53 \%$, the reason for this was indicated as the active wish to have children directly after surgery. In $22.8 \%$ (47/ 206), adequate postoperative pharmacological therapy was not administered or taken, which should be improved.

Surprisingly, the use of postoperative pharmacological therapy was associated with a higher risk to develop recurrence in multivariate logistic regression analysis. This may be explained by the fact that a high percentage of patients became pregnant after surgery, some several times, which may lower the risk of recurrence during the study time. Secondly, the duration and drug of pharmacological therapy was heterogeneous. The current gold standard for surgical endometriosis lesions resection is the laparoscopy. This was performed in a total of $63.1 \%$ of interventions in our patient population. In our study, a laparotomy was performed in $21.8 \%$ of patients. Mostly, this was intended beforehand since fertility-preserving and restorative interventions on the tubes and uterus are performed depending on the equipment of the particular hospital, as the use of a surgical microscope and microsurgical instruments is necessary.

Surgical access, on the other hand, had no effect on the rate of recurrence in our patient population. This observation corresponds to international data $[47,48]$.

\section{Stage-dependent postoperative pregnancy rate}

The postoperative pregnancy rate in our study was $65.8 \%(79 / 120)$ if the women wanted to have children. The average number of pregnancies was 1.4 and therefore higher than the postoperative pregnancy rates described in the literature, which are between 32.4 and $65.5 \%$ after the excision of a stage III and IV endometriosis lesions [24, 39, 41, 49, 50]. The birth rate was $80.5 \%$, and a previous pregnancy improved the chance of becoming pregnant again after surgery $(76.0 \%$ versus 61.4\%).

As expected, we were able to determine a statistically significant correlation between the onset of pregnancy and maternal age $(p<0.0017)$ in univariate analysis. Furthermore, a lower age $<35$ was the dominant statistically significant factor in multivariate analysis which was 
associated with a higher postoperative pregnancy rate $(p<0.003)$

A total of $76.7 \%$ of women up to the age of 34 years became pregnant, while only $48.9 \%$ of women from the age of 35 up were able to conceive. The fertility capacity decreases as a women age, and moreover, with the resection of ovarian endometrioma, there is a risk of reduction in the ovarian reserve and thus less likelihood of conceiving [50].

In most studies investigating the effect of surgical therapy of endometriosis with regard to several outcome parameters such as symptom relief, recurrence rate and pregnancy rate, the surgery was performed as laparoscopy $[25,33,36,39,51]$. A prospective study compared the effect of the resection of colorectal endometriosis lesions with laparoscopy and laparotomy on fertility and showed that the rate of spontaneous postoperative pregnancies was distinctly higher in the group with laparoscopic access [52]. Daraï et al. also showed that laparoscopic endometriosis lesions resection is associated with higher postoperative pregnancy rates than resection via laparotomy, and has similar positive effects on symptoms and the quality of life [53].

Our results substantiate these findings with regard to postoperative pregnancy rates after laparoscopic surgery, which were statistically higher (74.3\%) than after laparotomy $(61.3 \%)$ as well as after conversion surgery (42.1\%). The advantage of laparoscopy is likely to be found in the low formation of adhesions, since the tissue damage is lower overall [54]. In our collective patients, we had a high percentage of women with severe tubal damage who were treated by laparotomy to restore fertility, using surgical microscopy and microsurgical instruments. Possibly, the lower rate of postoperative pregnancy after laparotomy was caused by these unfavourable conditions of the fallopian tubes.

After complete resection of endometriosis lesions, the pregnancy rate was higher (68.5\%) than after incomplete excision at $41.7 \%$. However, the correlation was not statistically significant in the multivariate logistic regression analysis. The retrospective cohort study of Soriano et al. [51] was able to demonstrate that radical surgical removal that also included a procedure for intestinal and bladder surgery does not have to involve a decrease in fertility. Surgical therapy is able to restore the pelvic anatomy that is changed by endometriosis [10]. However, it is essential to strike a balance between complete resection and the preservation of the reproductive organs and their function. In addition to the risk of diminishing the ovarian reserve, attention must be paid to the formation of new or rather further adhesions [55].

A new and future possibility to preserve fertility can be oocyte vitrification for patients not only in oncological situations but also in situations such as severe endometriosis that may induce the risk of premature ovarian failure [56-58].

\section{Conclusion}

We found a high percentage of $65.8 \%$ of women who became pregnant, sometimes several times, after the excision of moderate or severe endometriosis lesions, a low intra- and postoperative rate of complications of $6.8 \%$, a high rate of complete or partial postoperative reduction in symptoms of $93.2 \%$ and a low rate of recurrence of $21.8 \%$ compared to international literature, which are very encouraging values. Some of our patients had undergone several previous surgeries, were already older with regard to fertility with an average age of 37 years and were surveyed sometimes after a very long postoperative interval.

Our results show that patients with moderate or severe endometriosis, individually tailored therapy concepts to preserve fertility and decrease the risk of recurrence can be promising.

\section{Supplementary information}

Supplementary information accompanies this paper at https://doi.org/10. 1186/s12905-020-01016-3.

Additional file 1. Patient's questionnaire.

Abbreviations

rASRM: Revised American Society for Reproductive Medicine; AMH: Anti Mullerian Hormone; GnRH: Gonadotropin Releasing Hormone; IVF: In-vitro fertilization; ICSI: Intracytoplasmatic sperm injection; ESHRE: European Society of Human Reproduction and Embryology

Acknowledgements

We are grateful to all the women who agreed to participate in the study.

Authors' contributions

CS: Project development, data analysis and interpretation, manuscript editing and writing. YW: Data acquisition and collection, data analysis and interpretation, manuscript writing. JB: Manuscript editing, manuscript revision, interpretation of data. GG-R: Data collection, surgeon, interpretation of data. MJ: Protocol development, surgeon, manuscript editing. PH: Manuscript editing, surgeon. SK: Project development, design of the work, manuscript editing. All authors read and approved the final manuscript.

\section{Funding}

We acknowledge the support by the German Research Foundation (DFG) and the Open Access Publication Fund of Hannover Medical School $(\mathrm{MHH})$ for the payment of the publication fees.

\section{Availability of data and materials}

The dataset that support the findings of this article belong to the Hannover Medical School. The survey data are not publicly available but can be obtained from the corresponding author upon reasonable request. The qualitative data cannot be made available in order to protect the confidentiality of study participants.

Ethics approval and consent to participate

All procedures performed in studies involving human participants were in accordance with the ethical standards of the institutional and/or national research committee and with the 1964 Helsinki Declaration and its later amendments or comparable ethical standards. Written informed consent was obtained from all participants. The access and use of the medical 
records was permitted by the Data Protection Officer of Hanover Medical School. The study was approved by the Ethics Committee of Hanover Medical School in 2017 (No: 3527-2017).

\section{Consent for publication}

This manuscript does not show or report personal data such as individual details or images. Therefore, consent for publication is not applicable.

\section{Competing interests}

The authors declare that they have no competing interests.

Received: 22 January 2020 Accepted: 7 July 2020

Published online: 13 July 2020

\section{References}

1. Finas D, Hüppe M, Diedrich K, Kowalcek I. Chronischer Unterbauchschmerz am Beispiel der Endometriose-Problempatientin in der Gynäkologie? Geburtshilfe Frauenheilkd. 2005;65:156-63.

2. Simoens S, Dunselman G, Dirksen C, Hummelshoj BA, Brandes I, Brodszky V, Canis M, Colombo GL, Deleire T, Falcone T, Graham B, Halis G, Horne A, Kanj O, Kjer JJ, Kristensen J, Lebovic D, Mueller M, Vigano P, Wullschleger M, D'Hooghe T. The burden of endometriosis: costs and quality of life of women with endometriosis and treated in referral centres. Hum Reprod. 2012;27(5):1292-9.

3. Kundu S, Wildgrube J, Schippert C, Hillemanns P, Brandes I. Unterstützende und hemmende Faktoren im Umgang mit der Endometriose aus Sicht der Patientinnen. Geburtshilfe Frauenheilkd. 2015;75:462-9.

4. Bulun SE. Endometriosis. N Engl J Med. 2009;360:268-79.

5. Giudice LC, Kao LC. Endometriosis. Lancet. 2004;364:1789-99.

6. American Society for Reproductive Medicine. Revised American Society for Reproductive Medicine classification of endometriosis: 1996. Fertil Steril. 1997;67(5):817-22

7. Haas D, Shebl O, Shamiyeh A, Oppelt P. The rASRM score and the Enzian classification for endometriosis: their strengths and weaknesses. Acta Obstet Gynecol Scand. 2013b;92(1):3-7.

8. Vercellini P, Trespidi L, De Giorgi O, Cortesi I, Parazzini F, Crosignani PG. Endometriosis and pelvic pain: relation to disease stage and localization. Fertil Steril. 1996;65:299-304.

9. Gupta S, Goldberg JM, Aziz N, Goldberg E, Krajcir N, Agarwal A. Pathogenic mechanisms in endometriosis-associated infertility. Fertil Steril. 2008;90(2): 247-57.

10. Evans MB, Decherney AH. Fertility and endometriosis. Clin Obstet Gynecol. 2017:60(3):497-502.

11. Pacchiarotti A, Frati P, Milazzo GN, Catalano A, Gentile V, Moscarini M. Evaluation of serum anti-Mullerian hormone levelst o assess the ovarian reserve in women with severe endometriosis. Eur J Obstet Gynecol Reprod Biol. 2014;172:62-4.

12. Goodman LR, Goldberg JM, Flyckt RL, Gupta M, Harwalker J, Falcone T. Effect of surgery on ovarian reserve in women with endometriomas, ednometriosis and controls. Am J Obstet Gynecol. 2016;215:589e1-6.

13. Ulrich U, Buchweitz O, Greb R, Keckstein J, von Leffern I, Oppelt P, Renner SP, Sillem M, Stummvoll W, De Wilde RL, Schweppe KW. For the German and Austrian societies for obstetrics and gynecology. National German Guideline (S2k): Guideline for the Diagnosis and Treatment of Endometriosis: Long Version - AWMF Registry No. 015-045. Geburtshilfe Frauenheilkd. 2014 Dec;74(12):1104-18.

14. Saleh A, Tulandi T. Reoperation after laparoscopic treatment of ovarian endometriomas by excision and by fenestration. Fertil Steril. 1999;72:322-4.

15. Prefumo F, Rossi AC. Endometriosis, endometrioma, and ART results: current understanding and recommended practices. Best Pract Res Clin Obstet Gynaecol. 2018 Aug;51:34-40.

16. Dunselman GA, Vermeulen N, Becker C, Calhaz-Jorge C, D'Hooghe T, De Bie B, Heikinheimo O, Horne AW, Kiesel L, Nap A, Prentice A, Saridogan E, Soriano D, Nelen W. ESHRE guideline: managment of women with endometriosis. Hum Reprod. 2014;29:400-12.

17. Chapron C, Vercellini P, Barakat H, Vieira M, Dubuisson JB. Management of ovarian endometriomas. Hum Reprod Update. 2002;8:591-7.

18. Ke X, Qian H, Kang L, Wang J, Xie Y, Chang Z. Clinical analyses of endometriosis after conservative surgery. Int J Clin Exp Med. 2015;8(11): 21703-6.
19. Guo SW. Recurrence of endometriosis and its control. Hum Reprod Update. 2009;15(4):441-61

20. Vercellini $P$, Crosignani $P G$, Abbiati A, Somigliana E, Viganò $P$, Fedele L. The effect of surgery for symptomatic endometriosis: the other side of the story. Hum Reprod Update. 2009;15(2):177-88.

21. Bozdag G. Recurrence of endometriosis: risk factors, mechanisms and biomarkers. Womens Health (Lond). 2015;11(5):693-9.

22. Nirgianakis K, Ma L, McKinnon B, Mueller MD. Recurrence patterns after surgery in patients with different endometriosis subtypes: a long-term hospital-based cohort study. J Clin Med. 2020;11:9(2).

23. Yap C, Furness S, Farquhar S. Pre and post operative medical therapy for endometriosis surgery. Cochrane Database Syst Rev. 2004:3:CD003678.

24. Sun TT, Chen SK, Li XY, Zhang JJ, Dai Y, Shi JH, Jia SZ, Wu YS, Leng JH. Fertility Outcomes After Laparoscopic Cystectomy in Infertile Patients with Stage III-IV Endometriosis: a Cohort with 6-10 years of Follow-up. Adv Ther. 2020;37(5):2159-68.

25. Wilson-Harris BM, Nutter B, Falcone T. Long-term fertility after laparoscopy for endometriosis-associated pelvic pain in young adult women. J Minim Invasive Gynecol. 2014:21:1061-6.

26. Wykes CB, Clark TJ, Chakravati S, Mann CH, Gupta JK. Efficacy of laparoscopic excision of visually diagnosed peritoneal endometriosis in the treatment of chronic pelvic pain. Eur J Obstet Gynecol Reprod Biol. 2006; 125:129-33.

27. Flüß E, Bond CM, Jones GT, Macfarlane GJ. The effect of an internet option and single-sided printing format to increase the response rate to a population-based study: a randomized controlled trial. BMC Med Res Methodol. 2014;14:104

28. Haas D, Chvatal R, Reichert B, Renner S, Shebl O, Binder H, Wurm P, Oppelt P. Endometriosis: a premenopausal disease? Age pattern in 42079 patients with endometriosis. Arch Gynecol Obstet. 2012;286:667-70.

29. Falcone T, Flyckt R. Clinical Management of Endometriosis. Obstet Gynecol. 2018;131(3):557-71.

30. Karaman Y, Uslu H. Complications and their management in endometriosis surgery. Womens Health (Lond). 2015;11(5):685-92.

31. Nicolaus K, Zschauer S, Bräuer D, Jimenez-Cruz J, Lehmann T, Rengsberger M, Diebolder H, Runnebaum IB. Extensive endometriosis surgery: rASRM and Enzian score independently relate to post-operative complication grade. Arch Gynecol Obstet. 2020;301(3):699-706.

32. Roman H, Chanavaz-Lacheray I, Forestier D, Magne E, Celhay O, Pasticier G, Susperregui J, Merlot B. Early postoperative complications in a multidisciplinary surgical center exclusively dedicated to endometriosis: a 491-patient series. Gynecol Obstet Fertil Senol. 2020;S2468-7189(20):30105-7.

33. Abbott JA, Hawe J, Clayton RD, Garry R. The effects and effectiveness of laparoscopic excision of endometriosis: a prospective study with 2-5 year follow-up. Hum Reprod. 2003;18(9):1922-7.

34. Raimondo D, Mattioli G, Casadio P, Borghese G, Ambrosio M, Arena A, Paradisi R, Del Forno S, Coppola F, Valerio D, Garattoni M, Golfieri R, Seracchioli R. Frequency and clinical impact of Dolichocolon in women submitted to surgery for rectosigmoid endometriosis. J Gynecol Obstet Hum Reprod. 2020;49(4):101697.

35. Riiskjær M, Forman A, Kesmodel US, Andersen LM, Ljungmann K, SeyerHansen M. Pelvic pain and quality of life before and after laparoscopic bowel resection for Rectosigmoid endometriosis: a prospective, Observational Study. Dis Colon Rectum. 2018;61(2):221-9.

36. Vercellini P, Fedele L, Aimi G, De Giorgi O, Consonni D, Crosignani PG. Reproductive performance, pain recurrence and disease relapse after conservative surgical treatment for endometriosis: the predictive value of the current classification system. Hum Reprod. 2006;21(10):2679-85.

37. Comptour A, Chauvet $P$, Canis M, Grémeau AS, Pouly JL, Rabischong B, Pereira B, Bourdel N. Patient quality of life and symptoms after surgical treatment for endometriosis. J Minim Invasive Gynecol. 2018;18:30405-9.

38. Ianieri MM, Mautone D, Ceccaroni M. Recurrence in Deep Infiltrating Endometriosis: A Systematic Review of the Literature. J Minim Invasive Gynecol. 2018;25(5):786-93.

39. Fedele L, Bianchi S, Zanconato G, Berlanda N, Raffaelli R, Fontana E. Laparoscopic excision of recurrent endometriomas: long-term outcome and comparison with primary surgery. Fertil Steril. 2006;85(3):694-9.

40. Tobiume T, Kotani Y, Takaya H, Nakai H, Tsuji I, Suzuki A, Mandai M. Determinant factors of postoperative recurrence of endometriosis: difference between endometrioma and pain. Eur J Obstet Gynecol Reprod Biol. 2016;205:54-9. 
41. Busacca M, Bianchi S, Agnoli B, Candiani M, Calia C, De Marinis S, Vignali M. Follow-up of laparoscopic treatment of stage III-IV endometriosis. J Am Assoc Gynecol Laparosc. 1999a;6(1):55-8.

42. Busacca M, Marana R, Caruana P, Candiani M, Muzii L, Calia C, Bianchi S. Recurrence of ovarian endometrioma after laparoscopic excision. Am J Obstet Gynecol. 1999b;180:519-23.

43. Angioni S, Pontis A, Dessole M, Surico D, De Cicco NC, Melis I. Pain control and quality of life after laparoscopic en-block resection of deep infiltrating endometriosis (DIE) vs. incomplete surgical treatment with or without $\mathrm{GnRHa}$ administration after surgery. Arch Gynecol Obstet. 2015;291(2):363-70.

44. Koga K, Takamura M, Fujii T, Osuga Y. Prevention of the recurrence of symptom and lesions after conservative surgery for endometriosis. Fertil Steril. 2015;104(4):793-801.

45. Vercellini P, Somigliana E, Daguati R, Vigano P, Meroni F, Crosignani PG. Postoperative oral contraceptive exposure and risk of endometrioma recurrence. Am J Obstet Gynecol. 2008;198:504e1-5.

46. Vlahos N, Vlachos A, Triantafyllidou O, Vitoratos N, Creatsas G. Continous versus cyclic use of oral contraceptives after surgery for symptomatic endometriosis: a prospective cohort study. Fertil Steril. 2013;100(5):1337-42.

47. Catalano GF, Marana R, Caruana P, Muzii L, Mancuso S. Laparoscopy versus microsurgery by laparotomy for excision of ovarian cysts in patients with moderate or severe endometriosis. J Am Assoc Gynecol Laparosc. 1996;3: 267-70.

48. Crosignani PG, Vercellini P, Biffignandi F, Costantini W, Cortesi I, Imparato E. Laparoscopy versus laparotomy in conservative surgical treatment for severe endometriosis. Fertil Steril. 1996;66:706-11.

49. Sõritsa D, Saare M, Laisk-Podar T, Peters M, Sõritsa A, Matt K, Karro H, Salumets A. Pegnancy rate in endometriosis patients according to the severity of the disease after using a combined approach of laparoscopy, $\mathrm{GnRH}$ agonist treatment and in vitro fertilization. Gynecol Obstet Investig. 2015;79(1):34-9.

50. The American College of Obstetricians and Gynecologists Committee on Gynecologic Practice and Practice Committee. Female age-related fertility decline. Committee Opinion No. 589. Fertil Steril. 2014;101(3):633-4.

51. Soriano D, Adler I, Bouaziz J, Zolti M, Eisenberg VH, Goldenberg M, Seidman DS, Elizur SE. Fertility outcome of laparoscopic treatment in patients with severe endometriosis and repeated in vitro fertilization failures. Fertil Steril. 2016;106(5):1264-9.

52. Daraï E, Lesieur B, Dubernard G, Rouzier R, Bazot M, Ballester M. Fertility after colorectal resection for endometriosis: results of a prospective study comparing laparoscopy with open surgery. Fertil Steril. 2011;95(6):1903-8.

53. Daraï E, Dubernard G, Coutant C, Frey C, Rouzier R, Ballester M. Randomized trial of laparoscopically assisted versus open colorectal resection for endometriosis: morbidity, symptoms, quality of life, and fertility. Ann Surg. 2010;251:1018-23.

54. Practice Committee of American Society for Reproductive Medicine in collaboration with Society of Reproductive Surgeons. Pathogenesis, consequences, and control of peritoneal adhesions in gynecologic surgery: a committee opinion. Fertil Steril. 2013;99(6):1550-5.

55. Wallwiener M, Brölmann H, Koninckx PR, Lundorff P, Lower AM, Wattiez A, Mara M, De Wilde RL. The anti-adhesions in gynecology expert panel (ANGE L). Adhesions after abdominal, pelvic and intra-uterine surgery and their prevention. Gynecol Surg. 2012;9:465-6.

56. Decanter C, d'Argent EM, Boujenah J, Poncelet C, Chauffour C, Collinet P, Santulli P. Endometriosis and fertility preservation: CNGOF-HAS Endometriosis Guidelines. Gynecol Obstet Fertil Senol. 2018;46(3):368-72.

57. Somigliana $E$, Vercellini P. Fertility preservation in women with endometriosis: speculations are finally over, the time for real data is initiated. Fertil Steril. 2020;50015-0282(19):32622-6.

58. Lantsberg D, Fernando S, Cohen Y, Rombauts $L$. The role of fertility preservation in women with endometriosis: a systematic review. J Minim Invasive Gynecol. 2020;27(2):362-72.

\section{Publisher's Note}

Springer Nature remains neutral with regard to jurisdictional claims in published maps and institutional affiliations.

Ready to submit your research? Choose BMC and benefit from:
- fast, convenient online submission
- thorough peer review by experienced researchers in your field
- rapid publication on acceptance
- support for research data, including large and complex data types
- gold Open Access which fosters wider collaboration and increased citations
- maximum visibility for your research: over 100M website views per year
At BMC, research is always in progress.
Learn more biomedcentral.com/submissions

